\title{
Differences in milk fat composition from four old sheep breeds
}

\author{
E. Viturro ${ }^{1}$, M. Schlattl ${ }^{1}$, H. Kienberger ${ }^{3}$, M. Rychlik ${ }^{3}$, M. W. Pfaffl ${ }^{1}$, and K. Frölich ${ }^{2}$ \\ ${ }^{1}$ Physiology, Technische Universität München, Munich, Germany \\ ${ }^{2}$ Arche Warder e.V., Warder, Germany \\ ${ }^{3}$ Department of Analytical Food Chemistry, Technische Universität München, Munich, Germany \\ Correspondence to: M. W. Pfaffl (pfaffl@wzw.tum.de)
}

Received: 27 March 2015 - Revised: 18 August 2015 - Accepted: 20 August 2015 - Published: 2 September 2015

\begin{abstract}
The present short communication presents a comparison between the milk fat composition of four old sheep breeds. All animals were fed the same diet and a milk sample was obtained at the same lactation day and analyzed for its major components, cholesterol concentration and a complete fatty acid profile. From all studied candidates, the Walachian breed (also when compared with modern breeds employed in the dairy industry) was determined to have the most suitable milk composition for human health.
\end{abstract}

\section{Background}

The role of dietary cholesterol and saturated fat in human health is presently one of the topics of high concern among scientific and health authorities. Although milk and dairy products have a relatively low amount of these fats compared to other food groups, the frequency of their consumption places them among their principal dietary sources (RoyoBordonada et al., 2003; Astrup et al., 2011). Sheep milk and dairy products are used in some regions as an alternative to cow milk products, even though their composition is much richer in fat than that of cattle (Raynal-Ljutovac et al., 2008).

It is well established that diet composition has a noticeable impact on animal performance and lipid profile in sheep milk, mainly through supplementation with plant (Luna et al., 2008; Bodas et al., 2010; Altenhofer et al., 2013) and fish oils (Toral et al., 2010). Animal breeding is another potential pathway to achieve this goal, but it is relatively unexplored in comparison to the abundant studies on feed supplementation. In this preliminary pioneer study, four old sheep breeds were tested as candidates for a healthier milk composition.

\section{Procedures}

\subsection{Animals and sampling}

Twenty sheep from four different ancient breeds (Racka, Soay, Walachian and Houtland), non-primiparous and aged 3 to 8 years, were kept at the Tierpark Arche Warder, a conservation center for old domestic animal breeds located in northern Germany (Schleswig-Holstein). Animals were given access to fresh pasture ad libitum, supplemented with concentrate, until 10 days before sampling, at which they were stalled and offered the same ration (fresh hay and concentrates) in order to allow for proper comparison. Sampling was chosen to be at lactation day 60 , at which time the metabolic stress associated with lactation had already passed. Therefore, the obtained values remain representative and comparable.

The entirety of the milk was first collected in a single container and posteriorly aliquoted in the definitive samples, in order to avoid the well-known unequal distribution of components at the beginning and end of the milking procedure. Samples were frozen and kept at $-20^{\circ} \mathrm{C}$ until analysis. 
Table 1. Milk composition from the four studied ancient sheep breeds.

\begin{tabular}{|c|c|c|c|c|c|c|c|}
\hline & \multicolumn{3}{|c|}{ Major milk components } & \multicolumn{4}{|c|}{ Composition of milk fat } \\
\hline & Protein $\%$ & Lactose \% & Fat $\%$ & SFA $\%$ & MUFA $\%$ & PUFA $\%$ & $\begin{array}{l}\text { Cholesterol } \\
\mathrm{mg} \mathrm{dL}^{-1} \text { milk }\end{array}$ \\
\hline Racka & 5.83 & 4.57 & 4.48 & 60.75 & 31.99 & 4.77 & 63.7 \\
\hline Soay & 5.71 & 4.71 & 4.49 & 59.68 & 32.43 & 5.48 & 52.0 \\
\hline Walachian & 5.14 & 5.18 & 3.33 & 60.40 & 32.70 & 4.46 & 32.8 \\
\hline Houtland & 4.98 & 4.89 & 2.61 & 73.82 & 20.44 & 3.33 & 25.9 \\
\hline
\end{tabular}

$\mathrm{SFA}=$ saturated fatty acids, MUFA $=$ monounsaturated fatty acids, PUFA = polyunsaturated fatty acids

\subsection{Milk analysis}

Three analysis experiments were carried out for each sample: major milk components determination, cholesterol concentration quantification and milk fatty acid profiling. The major milk components (percent fat, protein, and lactose) were analyzed with a MilkoScan-FT-6000 spectrometer at the accredited laboratory MPR Bayern e.V. (Wolznach, Germany). Cholesterol concentration was determined at the Department of Physiology of the Technische Universität München (Munich, Germany) as described by Viturro et al. (2010). Milk fatty acid profiling was performed at the Department of Bioanalytics of the same university with gas chromatography, using a Hewlett Packard GC instrument (HP/Agilent 6890 series, Agilent Technologies, Santa Clara, CA, USA). All results obtained were compared using independent sample $t$ tests.

\section{Results and discussion}

From the four analyzed breeds a clear distinction is visible comparing the major milk components: the Racka and Soay sheep breeds are more similar to industrial modern sheep breeds. Moreover, their milk is richer in fat and protein compared to Walachian and Houtland. In parallel, these two breeds show a significant lowest amount of cholesterol (see Table 1).

Although the Houtland breed provides the lower amount of fat and cholesterol in the milk, with only $2.61 \%$ and $25.9 \mathrm{mg} \mathrm{dL}^{-1}$ respectively, their fatty acid profile is the less desirable of the four studied breeds, with a significantly higher amount of saturated fat and subsequently lower amount of the healthier unsaturated fats.

Taken together, the Walachian breed was determined to be the candidate with the most attractive milk composition of the four studied breeds regarding human health and may be a suitable alternative to modern breeds. Their milk has very low amounts of fat, an optimal fatty acid profile and a relatively low amount of cholesterol compared to other ancient and modern sheep breeds (Luna et al., 2008; Bodas et al., 2010). It is important to point out that all observed differences are probably exclusively due to genetic reasons, as all animals were sampled at the same lactation day and fed the same ration before to the study. The present preliminary study should serve as a basis for future studies for this promising topic, with a larger amount of animals per group and, if possible, monitoring of the whole lactation cycle.

Acknowledgements. The authors would like to thank the H. Wilhelm Schaumann Stiftung for the financial support of this project.

Edited by: S. Maak

Reviewed by: two anonymous referees

\section{References}

Altenhofer, C., Spornraft, M., Kienberger, H., Rychlik, M., Herrmann, J., Meyer, H. H. D., and Viturro, E.: Effects of rapeseed and soybean oil dietary supplementation on bovine fat metabolism, fatty acid composition and cholesterol levels in milk, J. Dairy Res., 81, 120-128, 2013.

Astrup, A., Dyerberg, J., Elwood, P., Hermansen, K., Hu, F. B., Jakobsen, M. U., Kok, F. J., Krauss, R. M., Lecerf, J. M., LeGrand, P., Nestel, P., Riserus, U., Sanders, T., Sinclair, A., Stender, S., Tholstrup, T., and Willett, W. C.: The role of reducing intakes of saturated fat in the prevention of cardiovascular disease: where does the evidence stand in 2010?, Am. J. Clin. Nutr., 93, 684-688, 2011.

Bodas, R., Manso, T., Mantecon, A. R., Juarez, M., de la Fuente, M. A., and Gomez-Cortes, P.: Comparison of the fatty acid profiles in cheeses from ewes fed diets supplemented with different plant oils, J. Agric. Food Chem., 58, 10493-10502, 2010.

Luna, P., Bach, A., Juarez, M., and de la Fuente, M. A.: Influence of diets rich in flax seed and sunflower oil on the fatty acid composition of ewes' milk fat especially on the level of conjugated linoleic acid, n-3 and n-6 fatty acids, Int. Dairy J., 18, 99-107, 2008.

Raynal-Ljutovac, K., Lagriffoul, G., Paccard, P., Guillet, I., and Chilliard, Y.: Composition of goat and sheep milk products: An update, Small Rum. Res., 79, 57-72, 2008.

Royo-Bordonada, M. A., Gorgojo, L., de Oya, M., Garces, C., Rodriguez-Artalejo, F., Rubio, R., del Barrio, J. L., and MartinMoreno, J. M.: Food sources of nutrients in the diet of Spanish children: the Four Provinces Study, Brit. J. Nutr., 89, 105-114, 2003. 
Toral, P. G., Frutos, P., Hervas, G., Gomez-Cortes, P., Juarez, M., and de la Fuente, M. A.: Changes in milk fatty acid profile and animal performance in response to fish oil supplementation, alone or in combination with sunflower oil, in dairy ewes, J. Dairy Sci., 93, 1604-1615, 2010.
Viturro, E., Meyer, H. H. D., Gissel, C., and Kaske, M.: Rapid method for cholesterol analysis in milk and options for applications, J. Dairy Res., 77, 85-89, 2010. 